\title{
A educação popular e o cuidado em saúde:
}

\author{
um estudo a partir da obra de Eymard Mourão Vasconcelos
}

Luciano Bezerra Gomes ${ }^{(a)}$

Emerson Elias Merhy ${ }^{(b)}$

Gomes LB, Merhy EE. The popular education and the health care: a study from the work of Eymard Mourão Vasconcelos. Interface (Botucatu). 2014; 18 Supl 2: 1427-1440.

The article analyzes the conceptions about health care in authors of Popular Education in Health, with fundamental reference to the works of Eymard Mourão Vasconcelos published between 1994 and 2009. It is a literature research, qualitative, exploratory level, analytical and that besides of systematizing the formulations of this author, points to several possibilities for discussion with researchers of the theme of care. The texts were grouped into the following categories: power relations in health care; critiques to biomedicine, individual care, the approach to the family. It seeks to stimulate the production of new concepts from the integration between formulations of thinkers who have not themselves approached, despite it's potential thematic nearby.

Keywords: Popular Health Education. Health care. Qualitative research.
O artigo analisa as concepções sobre o cuidado em saúde em autores da Educação Popular em Saúde, tomando como referência fundamental a obra de Eymard Mourão Vasconcelos publicada entre 1994 e 2009. Trata-se de pesquisa bibliográfica, de natureza qualitativa, de nível exploratório e caráter analítico e que além de sistematizar as formulações deste autor, aponta para possibilidades de debate com diversos estudiosos do tema do cuidado. Os textos foram agregados nas seguintes categorias: relações de poder no cuidado em saúde; críticas à biomedicina; o atendimento individual; a abordagem à família. Procura-se estimular a produção de novos conceitos a partir da integração entre formulações de pensadores que não têm se aproximado, apesar de potenciais proximidades temáticas.

Palavras-chave: Educação Popular em Saúde. Cuidado em saúde. Pesquisa qualitativa.

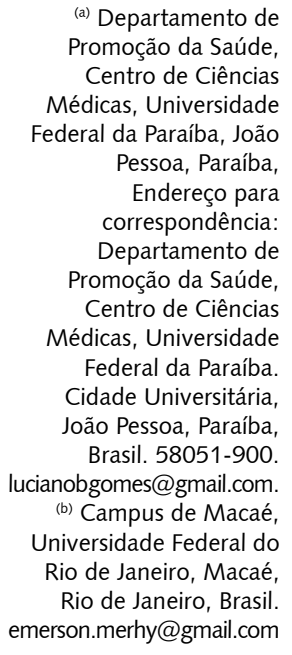

(a) Departamento de Promoção da Saúde, Centro de Ciências Médicas, Universidade Federal da Paraíba, João Pessoa, Paraíba, Endereço para correspondência: Departamento de Promoção da Saúde, Centro de Ciências Médicas, Universidade Federal da Paraíba. Cidade Universitária, João Pessoa, Paraíba Brasil. 58051-900. lucianobgomes@gmail.com.

(b) Campus de Macaé, Universidade Federal do Rio de Janeiro, Macaé,

Rio de Janeiro, Brasil. emerson.merhy@gmail.com 


\section{Introdução}

Este artigo é fruto de um estudo que tentou apontar as interfaces e possibilidades de diálogo entre as formulações de autores da Educação Popular em Saúde com autores que produzem conhecimentos sobre aspectos relacionados ao cuidado em saúde. Tal estudo se desenvolveu como parte do curso de mestrado realizado por um dos autores deste artigo, tendo o outro como orientador, junto à linha de pesquisa Micropolítica do Trabalho e o Cuidado em Saúde, do Programa de Pós-graduação em Clínica Médica da Faculdade de Medicina da Universidade Federal do Rio de Janeiro.

Como primeira etapa da pesquisa, realizamos uma revisão da literatura brasileira referente à Educação Popular em Saúde, onde apresentamos a compreensão de que este campo se formou, simultaneamente, como área de produção acadêmica e como dinâmico movimento social ${ }^{1}$. Em seguida, analisamos as formulações sobre o cuidado em saúde que se encontram em autores da Educação Popular em Saúde.

Para desenvolver esta etapa, identificamos os autores da Educação Popular em Saúde mais referenciados pelos pares. Entre eles, procuramos os que desenvolveram investigações relacionados ao cotidiano dos profissionais de saúde. Diante desses critérios, optamos por analisar a obra de Eymard Mourão Vasconcelos, tomando-a como indicativa da construção teórica desta matriz. Para além do reconhecimento acadêmico da relevante produção deste autor, também consideramos o caráter longevo de sua obra, tida como uma das fundadoras desta corrente, bem como sua inserção como um dos intelectuais orgânicos neste amplo movimento. Por tais características, acreditamos que seus textos reverberaram não apenas reflexões pessoais, mas que estão atravessados pelas construções coletivas que acompanharam o desenvolvimento do campo.

Metodologicamente, caracteriza-se como uma pesquisa bibliográfica de natureza qualitativa, de nível exploratório e caráter analítico. Para a abordagem do material, realizamos etapas sucessivas de leitura exploratória, seletiva e analítica, as quais executamos inicialmente sobre os 375 artigos detectados na base de dados da Scielo e que foram publicados até junho de 2009 com descritores relacionados à educação em saúde. A partir destes artigos, foram selecionados os 37 que mais permitiam contribuir com os interesses da análise, aos quais foram agregados 15 livros e 25 capítulos que apareciam neste material como mais relevantes, textos com os quais se produziu a primeira parte do estudo 1 .

Para desenvolver a segunda etapa da pesquisa, analisamos tudo que Eymard Vasconcelos divulgou em formato escrito, como livros, capítulos de livros, artigos, entre outros, durante os anos de 1994 e 2009. Este recorte temporal foi eleito por ter sido neste período que vários autores intensificaram o debate sobre as disputas em torno da clínica e o campo do cuidado em saúde, como se pode perceber nas produções desta época de Emerson Merhy, Gastão Campos, Luiz Cecílio, Laura Feuerwerker, Ricardo Ceccim, Alcindo Ferla, Túlio Franco, Ruben Mattos e Gustavo Tenório Cunha, entre outros.

Tomando este recorte temporal na obra daquele autor, realizamos nova abordagem de leitura exploratória, seletiva e analítica, quando utilizamos como referência alguns elementos da Hermenêutica Filosófica. Por limitações de espaço, sugerimos, aos interessados conhecer detalhadamente o método desenvolvido, a consulta ao artigo anteriormente publicado ${ }^{1}$ ou à dissertação que deu origem a ele $^{2}$.

\section{A obra de Eymard Vasconcelos}

Inicialmente, salientamos que Eymard não se coloca como um pesquisador "asséptico". Em tudo que escreve, explicita sua vinculação com os interesses do que ele, geralmente, denomina por classes populares. É tipicamente um pesquisador que toma sua própria implicação para análise e produção de conhecimentos ${ }^{3}$. Faz isso de maneira muito próxima ao que pretende Alcindo Ferla: "que a própria prática, ao invés de viés de pesquisa, possa tornar-se, no tensionamento com a teoria, uma ferramenta para o revezamento teoria e prática" ${ }^{4}$ (p.19, grifos do autor).

Percebe-se também nele um forte compromisso eticopolítico, ao ter a educação popular como orientadora metodológica. Entretanto, ele não realiza uma defesa acrítica do pobre em qualquer situação, acreditando se fazer necessário compreender as mudanças que vêm ocorrendo nas classes populares, visto as análises tradicionais estarem se apresentando insuficientes. Segundo Eymard, 
o profissional precisa perceber que a população é capaz de organizar e sistematizar pensamentos complexos sobre a realidade em que vive, ao mesmo tempo em que é preciso identificar quando há erros por parte da população 5 .

Muitos dos conceitos aqui expostos modificaram-se ao longo da obra deste autor. Embora reconheça tal caráter, não priorizamos apenas uma análise cronológica das questões colocadas. Tentamos categorizar os elementos mais relevantes segundo proximidade temática, associando formulações que tinham afinidade, mesmo que produzidas em contextos diferentes.

Por fim, sem se pretender exaustivo, apontamos perspectivas de diálogo entre as reflexões de Eymard e as produções de autores com quem ele não debate diretamente em seus textos. Tentamos, assim, uma dupla aproximação, pois muitos dos autores que colocamos para "dialogar" com Eymard também não discutem com ele quando refletem sobre o cuidado em saúde, possivelmente em virtude das produções dele serem mais vistas como relacionadas à educação em saúde. Acreditamos que as aproximações que propomos permitiriam enriquecer as diversas formulações que buscamos articular aqui.

\section{Educação Popular e o Cuidado em Saúde}

Um primeiro aspecto da obra de Eymard que destacamos é a sua concepção sobre o cuidado em saúde, que vai sendo forjada nas situações vivenciadas por ele junto às classes populares. Eymard pensa que certos problemas são muito profundos para serem curados, mas não para serem cuidados. Diante disso, ele formula o que toma por cuidado:

cuidar significa ocupar-se, aqui e agora, dos problemas passíveis de ser enfrentados, pondose à disposição de acordo com as condições exigidas por eles e não nas condições oferecidas tradicionalmente pelo serviço. O sofrimento não se anula, mas começa-se a remover-lhe motivos e mudam-se as formas e o peso com que este sofrimento entra no jogo da vida da família. Cuida-se dessas famílias em situação de risco não como prêmio por perceber seu esforço ou sua assimilação das orientações da equipe mas como resposta ao direito à cidadania de sujeitos vivendo situações que não lhes permitem buscar e lutar pelos recursos existentes nos precários e limitados serviços de saúde destinados às classes populares. $\mathrm{O}$ apoio familiar não pode ser um último teste para esta família se tornar operativa, mas espaço de vida a mais no qual lhe propiciamos alguns dos novos suportes que possam utilizar para compor seu próprio caminho de vida. Fazer-se responsável por membros incapazes de iniciativas próprias e em crise de uma família é evitar seu abandono em nome de uma propalada liberdade que as pessoas teriam para até mesmo não querer cuidar de sua saúde ou da de seus dependentes sem deixar, no entanto, de respeitar suas diretrizes de vida ${ }^{5}$ (p.153).

Tal formulação se constituiu a partir da análise de experiências de cuidado a famílias vivendo em comunidades de extrema vulnerabilidade, que passavam por situações de intensa crise, e isso, de certa forma, está impregnado na noção que desenvolve ${ }^{5}$. Mesmo reconhecendo tal contexto, consideramos ser este um bom fragmento para iniciarmos a compreensão do que Eymard propõe para pensar o cuidado em saúde, desde que complementado por outros aspectos presentes em várias passagens analisadas no presente artigo. De certa forma, no trecho acima, há uma síntese do que este autor toma como referência ao propor arranjos para o cuidado. Nesta proposição, evidencia-se uma concepção eminentemente política do cuidado, onde o fundamental é colocar-se à disposição das necessidades do outro. Também que para lidar com a heterogeneidade do sujeitos, o profissional precisa abordá-los em suas singularidades, em uma complexidade social que se precisa compreender ${ }^{6}$.

Afirma que os problemas de saúde extrapolam as dimensões orgânicas das pessoas. Entre outros aspectos, Eymard admite as dimensões afetivas como inerentes ao cuidado; ele acredita que "resultados positivos de nossa atuação construíram-se, em grande parte, por elementos afetivos transmitidos por nosso olhar e nossos gestos, fora do controle de nossa intencionalidade profissional" 5 
(p. 121). Ele sustenta que, para cuidar, o profissional deve "responsabilizar-se mesmo não tendo soluções técnicas bem-definidas, não deixando que pessoas, com pouca capacidade de enfrentamento da crise de vida a que estão submetidas, fiquem abandonadas e sozinhas"7. (p.301). Ao invés das relações disciplinares, é um compromisso eticopolítico que deve orientar o cuidado. Aproxima-se, aqui, de formulações como a de Ruben Mattos: "o que caracteriza o melhor cuidado é sua contribuição para uma vida decente, e não a sua cientificidade"8 (p.121). Isto não significa rejeitar os aportes que a ciência traz para o desenvolvimento do cuidado, mas os subsume ante outras relações.

Ainda, Eymard propõe associarmos a responsabilização profissional com o reconhecimento da capacidade do outro em determinar sua própria vida e que se tome a autonomia do outro como pilar para a prática do cuidado em saúde. Discorda do julgamento moral muitas vezes realizado por profissionais e equipes de saúde ao tentarem enquadrar as atitudes das pessoas em padrões de comportamento aceitáveis. Em diversas ocasiões, tais avaliações servem para que os profissionais determinem as pessoas que merecem ou não o atendimento adequado. Ao contrário, como citado anteriormente, ele defende que se cuide das famílias "como resposta ao direito à cidadania de sujeitos vivendo situações que não lhes permitem buscar e lutar pelos recursos existentes nos precários e limitados serviços de saúde destinados às classes populares"5 (p.153).

Para assumir tal atitude, não podemos continuar a ver apenas as carências existentes na população. Eymard crê que precisamos aprender também com as suas potências, as intensidades presentes nas suas vidas. Destaca a necessidade de se compreenderem e valorizarem as potencialidades dos indivíduos e grupos sociais. Enfatiza que precisamos trabalhar com os aspectos positivos, ricos, da vida das classes populares. "Suas atitudes seriam [...] mais bem compreendidas se analisadas pela ótica da busca de INTENSIDADE no viver" 5 (p.109, grifo do autor).

Para realizar práticas de saúde que permitam o desenvolvimento desta concepção de cuidado, superando as diferenças de perspectivas identificadas entre trabalhadores e população, este autor aponta a educação popular como caminho. Ao mesmo tempo, ele faz diversas reflexões sobre as necessidades de avanços no debate da educação popular, em relação a como tal discussão ocorria nas suas primeiras experiências, durante os anos de repressão política das ditaduras militares na América Latina. Diante disso, Eymard sugere o que pensa ser uma Educação Popular em Saúde que se insira dinamicamente no momento atual.

De acordo com ele, o trabalho comunitário exige dos profissionais o aprendizado e o desenvolvimento de novas técnicas de cuidado e aposta na educação popular como método para levar ao desenvolvimento deste novo modo de se produzir saúde. Para além do ensino, aprendizagem e comunicação, ele julga a educação popular como método adequado para conduzir a gestão das práticas de saúde e como algo que redefine todo o funcionamento do serviço, $0^{5,9}$.

Ele também enfatiza que a educação popular precisa agregar, em seu instrumental metodológico e em suas temáticas, novas dimensões. Assevera que os profissionais de saúde devem aprender mais com a população em relação à valorização da intuição, da emoção e dos sentidos impressos à existência. Propõe que a elaboração conjunta de sentimentos e emoções, o diálogo sobre os sonhos e ideias utópicas sejam vistos como centrais para o desenvolvimento de novos educadores populares ${ }^{7,10}$. Ele crê que o investimento em dimensões culturais e subjetivas - embora boa parte dos profissionais e gestores não percebam estes aspectos como prioritários (sequer relevantes) para o sistema de saúde representa aspecto central na luta pela saúde ${ }^{5}$.

Passando a abordar a organização dos serviços segundo as proposições de Eymard, um primeiro aspecto a salientar é que ele defende a integração entre a atenção individual e coletiva, não devendo haver divergências e contraposições entre estas dimensões, que considera complementares, da atuação dos profissionais de saúde?.

Ele situa o vínculo como central para a produção do cuidado. E para além do vínculo burocrático entre equipe e usuários, aponta para uma relação de intensa interação com o outro. Acredita no poder de um envolvimento amoroso entre trabalhador e usuários que permita a comunicação entre eles, acentuando que as diretrizes da responsabilização, vínculo e a produção de alteridade com usuários são terapêuticas também para os profissionais ${ }^{7,10}$. Ele diz que tal relação "torna o sofrimento do 
outro significativo para o profissional", sendo fundamental "para o desmascaramento da ilusão na capacidade do conhecimento científico dar conta de resolver a totalidade das necessidades de saúde da população"7 (p.299). Tal valorização do vínculo se aproxima da formulação de Luiz Cecilio, que propõe um arranjo teórico para analisar as "múltiplas dimensões da gestão do cuidado", em que considera como imanentes, no trabalho em saúde, o que denomina como as dimensões "individual", "familiar", "profissional", "organizacional", "sistêmica" e "societária" da gestão do cuidado11,12.

Eymard vê inadequações na racionalidade médica hegemônica para lidar com a miséria, organizando-se a partir de serviços que selecionam os problemas de acordo com as ofertas que disponibiliza, e não segundo as necessidades de saúde dos usuários. Ele reconhece uma desresponsabilização sistêmica em relação à populaçãa ${ }^{5}$. Tal perspectiva se aproxima da concepção de Merhy ${ }^{13}$, para quem os serviços de saúde devem se organizar tomando por objeto as necessidades de saúde dos usuários, concepção presente também em outros autores ${ }^{14}$.

Eduardo Stotz (apud ${ }^{15}$ ), ao debater o tema das necessidades de saúde, chega às seguintes conclusões: as necessidades de saúde são sempre histórica e socialmente construídas, dizendo assim respeito a toda a sociedade, mas a doença tem características singulares, exigindo sua atenção em nível individual; sendo assim, é necessário trabalhar os valores subjetivos; ao mesmo tempo, então, necessidade de saúde não pode ser identificada nem na perspectiva do indivíduo desarticulado de suas relações sociais, nem de uma estrutura social totalizante.

Dialogando com a produção de Stotz, Luiz Cecilio ${ }^{16}$ oferta uma taxonomia operacional das necessidades de saúde, a fim de ser trabalhada criticamente pelos profissionais no seu cotidiano. Este autor propõe, então, a categorização em quatro grandes conjuntos de necessidades: de se ter boas condições de vida; de se ter acesso a toda tecnologia capaz de melhorar e prolongar a vida; de se ter vínculos (a)efetivos entre cada usuário e uma equipe ou profissional de saúde; de se ter graus crescentes de autocuidado e de autonomia na escolha dos modos de andar a vida ${ }^{15,16}$. Partindo desta taxonomia, Merhy ${ }^{17}$ acrescenta a necessidade de ser reconhecido pelo outro em sua singularidade, sujeito de direito e cidadão nominal, enfim, o sujeito em sua alteridade.

Nem é preciso enfatizar a relação entre o que estes autores oferecem para se pensar as necessidades de saúde e algumas das reflexões sobre o cuidado em saúde, oxigenadas a partir da educação popular, desenvolvidas por Eymard Vasconcelos.

Por fim, diante de tantas possibilidades e desafios, Eymard salienta a importância de os profissionais conhecerem os limites de sua atuação e reconhecerem que há outros atores envolvidos na luta pela melhoria das condições de vida da população. Que saibam que as metas almejadas, diversas vezes, exigem muito tempo para serem alcançadas. Estas ponderações ele considera necessárias para evitar frustrações e permitir que o profissional torne sua vida mais prazerosa, seja feliz e, assim, cada vez mais se insira na dinâmica social do lugar em que mora? ${ }^{9}$.

Nas próximas páginas, desenvolveremos alguns conceitos específicos das produções de Eymard que têm relação com os desafios postos para uma renovação da clínica e para a produção do cuidado em saúde, nas suas diversas dimensões. Neste sentido, organizamos as contribuições e os debates em torno da obra deste autor nos seguintes tópicos: relações de poder no cuidado em saúde; críticas à biomedicina; o atendimento individual; a abordagem à família.

\section{Relações de poder no cuidado em saúde}

Eymard afirma que a atenção médica tradicional é injusta não apenas por segregar os trabalhadores, mas por reforçar e recriar, ao nível das microrrelações, as estruturas de dominação da sociedade 9 . Em determinados momentos, ele se aproxima ao que referia Maria Cecilia Donnangelo, para quem uma das funções da medicina na sociedade capitalista seria desenvolver um papel ideológico, fazendo crer que os problemas de saúde, que tinham determinações políticas, econômicas e sociais, estavam assentados e dependeriam de modificações individuais dos sujeitos ${ }^{18}$. 
Entretanto, mais do que estas análises dos interesses macroeconômicos do capital, Eymard discute no âmbito dos micropoderes; ele atua e reflete onde opera a micropolítica, buscando referência para isto na produção de Michel Foucault'19. Segundo Eymard, embora aparentemente não tenham "poder formal" diante de diversas situações, os trabalhadores da saúde podem mobilizar um "poder simbólico" significativo ${ }^{5}$. Ao salientar a necessidade de se assumir que o profissional de saúde exerce tais poderes, ele defende que isso deve ser foco de problematização coletiva, tornando as relações de poder mais explícitas e permitindo seu redirecionamento, sempre que necessário9.

Para ele, os trabalhadores de saúde tendem a desenvolver considerável poder diante da população e das autoridades locais. Estas relações existem, queira o profissional ou não, e é importante problematizá-las na perspectiva de que sejam submetidas à dinâmica coletiva dos sujeitos da comunidade. Infelizmente, em muitas ocasiões, os trabalhadores desenvolvem estas relações de modo que somente produzem mais poder para si, afastando-se cada vez mais da população ou, o que pode ser pior, fazendo com que ela fique dependente ou submissa a eles. Um bom modo de lidar com isto, segundo Eymard, é colocar sempre em discussão coletivamente as medidas que devem ser tomadas e o profissional evitar fazer pela população as coisas que ela mesma precisa realizar, mesmo que deste modo o processo pareça demorar mais ou apresentar certos retrocessos 9 .

O usuário, por sua parte, tensiona os serviços diante de situações de acesso burocratizado, age com humor ou ironia, ou mesmo não adere a condutas prescritas pelos profissionais, tais medidas sendo sinais da sua autonomia ${ }^{5}$. Em especial, frente a lógicas disciplinares de se regular a produção da vida.

Estas resistências, entretanto, muitas vezes, não se exprimem como críticas realizadas de forma explícita, principalmente quando se dirigem aos profissionais de nível superior, como os médicos. Para compreender isto, Eymard desenvolve uma análise das relações de poder embutidas na linguagem. Segundo ele, "a linguagem não é somente instrumento de comunicação, mas também instrumento de poder. Competência linguística implica poder de impor a recepção" ${ }^{5}$ (p.54). Tal perspectiva se aproxima da concepção que nos expõe Foucault, quando este fala que "o discurso não é simplesmente aquilo que traduz as lutas ou os sistemas de dominação, mas aquilo por que, pelo que se luta, o poder do qual nos queremos apoderar" 20 (p.10). Outros autores que desenvolvem profunda reflexão sobre a linguagem como poder são Gilles Deleuze e Félix Guattari. Segundo eles, ao desenvolvermos a linguagem, estamos inserindo as pessoas em regimes de signos que são, em si, relações sociais de poder. Afirmam que "a linguagem não é mesmo feita para que se acredite nela, mas para obedecer e fazer obedecer"21 (p.12). Identificamos, nesta discussão sobre a linguagem, alimentada por Eymard, Foucault, Deleuze e Guattari, uma importante contribuição para o cuidado. Isto, por nos exigir analisar as maneiras como, em distintos momentos, nos posicionamos diante destas complexas relações de poder. Sempre estamos dentro delas, operando nelas. Ter consciência disto é importante para ajudar na nossa definição enquanto sujeitos políticos, mesmo (e essencialmente) quando estivermos atendendo as pessoas em nossos consultórios.

Para além de compreender os aspectos micropolíticos presentes nas relações entre trabalhadores e usuários, Eymard nos coloca a pauta sobre as relações que estabelecemos com as lutas populares, que não deixa de ser outro âmbito, mais coletivo, de se pensar o cuidado. Para ele, os processos desencadeados podem fortalecer a perspectiva de que os serviços de saúde devem ser controlados pela população organizada. Embora haja arcabouço legal neste sentido, as leis e portarias não garantem a efetiva participação da população nas definições políticas dos serviços de saúde. Acredita que somente a luta organizada pode garantir esta diretriz fundamental do sistema de saúde, embora considere que precisamos desenvolver estratégias de se enfocarem os interesses dos grupos populares menos organizados também ${ }^{7,22}$.

Uma última reflexão sobre as relações de poder entre trabalhadores e população que trazemos da leitura de Eymard, refere-se à compreensão da violência no meio popular. Ele interpreta que a violência nas periferias representa caráter de manifestação da luta de classes, exprimindo revolta pelas condições de vida a que estão submetidos os pobres. Entretanto, boa parte da energia dispendida por tal revolta se perderia ao não se integrar a processos de transformação social. Tal contexto de violência, entretanto, ainda tem resguardado os profissionais de saúde, sendo excepcionais as situações em que 
há ameaça ou mesmo agressão a estes trabalhadores. Embora tenha pequena dimensão quantitativa, segundo ele, a repercussão de eventuais situações tende a ser exacerbada ${ }^{5}$.

A ampliação da violência social tem sido, na visão de Eymard, um dos fatores que mais tem sido utilizado para justificar a necessidade de distanciamento em relação à vida dos pobres. $O$ trabalhador tende a se fechar, desenvolvendo atitudes formais e distantes como estratégia de autoproteção. Desvia sua sensibilidade para outros aspectos, impedindo que haja aproximação afetiva com os usuários, ficando tal atitude de maior abertura restrita a poucas pessoas que, por diversos motivos, galgam o acesso aos seus afetos. Segundo ele, para lidar com a eventual ameaça de violência e retaliação por parte de pessoas da população, a melhor arma que os profissionais têm é o vínculo e a publicização de suas ações 5 .

\section{Críticas à biomedicina}

Eymard acredita que a concepção de ciência que orienta a medicina nos torna insensíveis e nos bloqueia a visão de diversas dimensões da vida das pessoas. E reconhece que a medicina científica moderna se sustentou nos pilares do paradigma newtoniano-cartesiano de explicação da vida humana e de suas alterações na normalidade, no que se convencionou pelo termo de modelo biomédico, o qual, a partir das últimas décadas, por diversos motivos, estaria passando por uma crise ${ }^{5,7}$.

Diante disto, Eymard desenvolve, então, uma importante reflexão sobre a inadequação das condutas médicas tradicionalmente desenvolvidas na medicina liberal, quando elas são direcionadas para as classes populares. Para ele, "a conduta médica padrão é construída em outros ambientes sociais e institucionais. Pressupõe disponibilidade do paciente para uma série de procedimentos antes do tratamento" ${ }^{5}$ (p.188). Entretanto, afirma que seria difícil perceber as insatisfações da população com as atividades desempenhadas pelos serviços de saúde, pois as pessoas insatisfeitas tendem a simplesmente não retornar. Para construir outra lógica de atuação, o profissional precisaria apreender as mediações existentes entre os elementos estruturais da realidade, que condicionam a vida dos usuários, e os processos patológicos sobre o corpo e a vida. Diante de situações complexas, seria sobre as mediações entre estas duas dimensões que o profissional poderia atuar, impactando-as.

Para lidar com a complexidade do cotidiano da vida das classes populares, Eymard identifica as limitações das disciplinas tradicionalmente integradas à clínica. Defende, então, a educação popular como capaz de redefinir as relações que os profissionais desenvolvem entre as diversas disciplinas que dominam com a realidade onde estão tentando intervir. Para tal redefinição, ele entende que a prática clínica se apresenta como cenário privilegiado 5 .

Um autor que dá forte ênfase à necessidade se desenvolver outra prática clínica é Gastão Campos. Ele considera que uma reforma médico-sanitária deveria trabalhar uma total transformação da clínica, em que esta precisaria incorporar na rotina cotidiana processos de trabalho individuais e coletivos ${ }^{23}$. Este autor desenvolve várias análises e críticas aos modos tayloristas ${ }^{24,25}$ de se organizar o trabalho em saúde sugerindo novos arranjos organizacionais, baseados na cogestão dos coletivos, bem como propõe uma intensa reconstrução dos saberes que baseiam o trabalho em saúde, apostando no desenvolvimento do que ele denominou por clínica ampliada. Campos indica como prioritário se reformular o objeto de saber e intervenção da clínica, que, para além da doença, agregaria dialeticamente o sujeito e seu contexto como objetos ${ }^{26,27}$.

\section{$\mathrm{O}$ atendimento individual}

Ao abordar o atendimento individual, Eymard reflete bastante sobre a consulta médica. Ele considera que há uma rotina na consulta que permite a construção ordenada da história de vida (ou pelo menos nosológica) do sujeito. Que o diálogo com o outro fica mais rico com a exposição do corpo ao exame físico, permitindo o acesso a elementos não informados ou disfarçados pelo usuário, isto tudo envolto em uma intensificação da confiança e da cumplicidade entre os dois. Que se explora o 
sofrimento até se construir um projeto de superação do mesmo. Ainda, que o médico pode enriquecer seu papel ao compreender a maneira como o usuário integra em sua vida o conjunto de ações a ele direcionadas na consulta. Para este autor, lidar com os valores do usuário é uma estratégia que enriquece a terapêutica, aumentando a chance de seguimento dos novos pactos construídos para o andamento da vida do usuário, bem como para o apoio profissional a ele destinado ${ }^{5}$.

Neste sentido, Eymard concorda com algumas proposições defendidas por Kurt Kloetzel para organizar o atendimento individual. Para melhor conduzir a consulta na atenção básica, segundo Kloetzel, podemos realizar, nos primeiros atendimentos individuais, uma entrevista mais extensa se limitarmos os exames físicos ao que é necessário para orientar as condutas clínicas iniciais, deixando para ir conhecendo melhor os sujeitos nos atendimentos subsequentes. Esta prática de um exame físico seletivo orientado pela anamnese ajudaria a evitar erros em virtude de possíveis achados casuais em um desnecessário exame pretensamente "mais extenso e completo", por sinal, impossível de ser efetivamente realizado ${ }^{28}$. Deste modo, poderíamos, desde o início, priorizar a análise da maneira como os sujeitos significam seus adoecimentos, dialogando com eles. Os atendimentos de retornos e visitas domiciliares assumiriam, assim, papéis essenciais e deveriam ser encarados sempre como parte de uma investigação criteriosa, não da doença, mas dos modos como os sujeitos andam na vida9.

$O$ atendimento individual, segundo Eymard, deve ser encarado como um espaço essencial de atuação política e que pode ter caráter educativo ou não, de acordo com o modo como ele é desenvolvido. O profissional de saúde deveria ajudar a população a compreender os motivos dos processos coletivos de adoecimento que acometem sua família, e seria neste processo de conscientização que se desenvolveria a posição política dos sujeitos. Este momento de atendimento individual, geralmente, está limitado a encontros curtos entre profissional e usuário, demandando preparação para aproveitá-lo adequadamente. E ele não fala somente de conhecimentos técnicos, mas também da realidade em que a população está inserida. Enfatiza que a educação em saúde, que geralmente é trabalhada como elemento para a saúde coletiva, deve ser vista como um saber necessário para o atendimento clínico individual ${ }^{7,9,10}$.

Eymard defende que o profissional de saúde precisa superar o distanciamento e se deixar, consciente e inconscientemente, afetar com a intensidade de emoções que são mobilizadas no trabalho em saúde. É fundamental integrar a dimensão afetiva como parte relevante do trabalho em saúde: "para cuidar da pessoa inteira, é preciso estar presente como pessoa inteira"10 (p.68). Aqui, ele se aproxima da concepção do encontro na saúde entre trabalhador-usuário como espaço intercessor, como é formulado por Emerson Merhy. Este autor recorre ao conceito deleuziano, concebendo como trabalho intercessor o agir em saúde, o qual produz ações de saúde com valor de uso no desenvolvimento de modos mais autônomos de se caminhar na vida. Para ele, enquanto em diversos tipos de trabalho a relação produção/consumo é mediada pelo mercado (através da relação de vários produtos com valores de uso e de troca), na saúde, tal interseção se dá de imediato, com produção e consumo ocorrendo simultaneamente no ato do trabalho vivo ${ }^{13,29}$.

Merhy ${ }^{13}$ identifica que os serviços, hegemonicamente, operam a partir de problemas específicos, dentro da lógica do modelo neoliberal das profissões, que subordina a dimensão cuidadora às dimensões profissionais específicos, tendo o saber médico como central, empobrecendo os núcleos específicos dos demais trabalhadores da saúde, inclusive em suas dimensões cuidadoras. Para superar tal situação, a dimensão cuidadora deveria ter a centralidade no trabalho em saúde, sendo preciso que o trabalho vivo, orientado pelas tecnologias leves e leve-duras, organizasse os diferentes processos produtivos fundamentais para a construção de um trabalho intercessor produtor de autonomia.

Se usasse tais conceitos em suas produções, acreditamos que Eymard defenderia a necessidade de a dimensão cuidadora tomar a centralidade no trabalho em saúde; ele consideraria que a Educação Popular em Saúde, além de ser uma tecnologia leve-dura, teria grande capacidade de ajudar a desenvolver novas tecnologias leves para o trabalho em saúde; ainda, que a autonomia e a potência produtora de vida dos usuários deveriam ser orientadoras das relações produzidas no trabalho intercessor.

Prosseguindo, identificamos na obra de Eymard a radical defesa do diálogo como estratégia capaz de definir a melhor conduta a ser tomada na prática clínica. Ao admitir as disputas e diferentes 
perspectivas entre trabalhadores e usuários, Eymard propõe estruturar um atendimento individual baseado no diálogo, em que profissional e usuário, portadores de saberes diferentes e ambos necessários, possam aprender juntos os melhores caminhos a serem trilhados. Estes espaços dialógicos seriam essenciais para que os profissionais construíssem, em parceria com os usuários, intervenções a partir de seus conhecimentos biológicos e sociais mediados pelos saberes dos usuários sobre a própria dinâmica de vida, os quais iriam compreendendo melhor. Nesta relação, os usuários, por sua vez, adquiririam conhecimentos técnicos que poderiam ajudar nas suas lutas individuais e coletivas ${ }^{9,30}$.

De modo próximo, Luis Claudio de Carvalho valora o usuário como sujeito do processo de cuidado e toma por analisador das relações entre trabalhador e usuários o que ele denominou por disputa de planos de cuidado, ao reconhecer como legítimo o embate de diferentes planos de cuidado construídos por eles. Entretanto, disputa, para este autor, não representa, necessariamente, conflito num sentido destrutivo, podendo ser algo positivo, desde que adequadamente elaborada pela equipe. Ele valoriza a existência de "um processo efetivo de disputa pelo cuidado em saúde, não sendo um momento negativo de resistência, mas uma parte fundamental para compor os planos terapêuticos" ${ }^{31}$ (p.13). Carvalho considera as divergências de projetos, que sempre ocorrem no cotidiano, como uma potência para a atenção à saúde, fazendo a ponderação de que isto dependerá da maneira como as equipes compreendem e lidam com elas. "Essa disputa opera várias lógicas, como as profissionais, as éticas e as políticas. Assim, esta situação tem o potencial de propiciar o aperfeiçoamento do trabalho em saúde desenvolvido pelos profissionais e os cuidadores" 31 (p.24).

Por fim, Eymard destaca que o atendimento individual, por mais que seja potente, também tem seus limites, entre os quais destaca: a identificação dos problemas e a construção das alternativas são realizadas individualmente, os usuários teriam assim maiores dificuldades em constatar os processos coletivos em que estão envolvidos; as alternativas ficam menos ricas por não contarem com a participação de outros olhares ${ }^{9}$. Para superar estes problemas, deveríamos buscar a ampliação dos interlocutores na construção do cuidado, seja através de atendimentos voltados para o conjunto das famílias, ou desenvolvendo ações fora do serviço de saúde voltadas para os grupos sociais.

\section{A abordagem à família}

Um dos temas mais frequentes e relevantes na produção de Eymard é a necessidade de o profissional alargar sua abordagem para os grupos familiares, de aprender a lidar com as famílias, entendendo-as como produtoras de cuidados que são essenciais e que tornam muito ricas as possibilidades de apoio nas classes populares. Os cuidados que são produzidos em casa, na sua visão, devem ser valorizados não apenas pelo seu papel na biologia da doença, mas em virtude da mobilização de afetos e significados que provoca na pessoa doente, bem como no conjunto de pessoas que se envolvem na sua execução.

Para Eymard, um ponto central é o conceito de família com que se trabalha, sendo importante entendê-la como algo em constante transformação. Tal compreensão se faz necessária, a fim de que se evitem atitudes moralistas perante aquelas que não se encaixam no tradicional padrão nuclear. Diante de situações complexas, é essencial abandonar a concepção a que se recorre comumente de "família desestruturada", sendo necessário entender como cada uma está permanentemente se reestruturando. Para além da estrutura, reconhecer os fluxos contínuos de constituição e transformação das relações entre seus membros. A abordagem a uma família deve buscar processos constantes de desterritorialização seguidos de reterritorialização ${ }^{32}$. Esta questão é central, pois os profissionais de saúde são formados para diagnosticar e tratar os indivíduos e, muitas vezes, o momento em que um membro da família melhora é justamente quando o outro descompensa. O sintoma circula e o cuidado deve ser amplo e permanente ${ }^{33}$.

Um aspecto relevante a se considerar nas famílias das classes populares é o papel que as mulheres assumem, de cuidadoras e batalhadoras por melhores condições de saúde para os parentes. Elas também têm papel importante na manutenção de redes de apoio social entre o conjunto dos membros das comunidades ${ }^{6,34}$. 
Eymard valoriza a construção de oportunidades de análise fora do contexto em que geralmente os profissionais se relacionam com as pessoas das classes populares. Em algumas situações, há um desencontro entre o diagnóstico médico e a percepção de saúde dos usuários. O profissional precisa compreender tais singularidades nas maneiras das famílias lidarem com a própria vida, evitando definir uma conduta "adequada" e passar a exigi-la indistintamente de todas as pessoas ${ }^{5}$.

O acompanhamento familiar é potente para lidar com parte das limitações dos atendimentos individuais, mas diante de uma população heterogênea, torna-se fundamental concentrar energias em algumas situações, como estratégia para garantir a equidade. Entretanto, vale salientar que, muito mais relevante que a identificação de determinados fatores de risco estanques, a dinâmica familiar e as redes socais de apoios a que ela se articula é que conseguem ser preditoras da maior ou menor vulnerabilidade a que estão submetidas. Para trabalhar com tais pessoas, além de atendimentos individuais e familiares no consultório, seria importante o acompanhamento sistemático com visitas domiciliares ${ }^{5,30}$.

O entendimento profundo destas dinâmicas exigiria dos trabalhadores encarar as relações destas famílias de forma mais complexa do que geralmente tem sido feito na maioria dos serviços. Eymard enfatiza a necessidade de se abordar de maneira ampla a dinâmica familiar para se produzir um cuidado mais adequado e eficiente. Para ele, ao invés de evidenciar a eventual falta de solidariedade entre as pessoas, seria mais importante trabalhar com a superação das dificuldades existentes nas formas de ajuda mútua existentes ${ }^{5}$.

Segundo Eymard, a família e a vizinhança apresentam importante papel no desenvolvimento das redes de apoio social, consideradas uma das iniciativas da população que tem grande efeito no fortalecimento da capacidade de autocuidado e de conseguir graus crescentes de autonomia ${ }^{7}$, necessidades de saúde relevantes, segundo a taxonomia desenvolvida por Cecilio ${ }^{16}$. Eymard defende que os profissionais de saúde têm um papel importante no acionamento e no fortalecimento de redes de apoio social junto à população ${ }^{5}$. Nas suas proposições, consideramos que consegue ofertar muitas reflexões em relação às dimensões individual, familiar e profissional da gestão do cuidado, segundo as denominações propostas por Cecilio ${ }^{11,12}$ em sua cartografia.

\section{Considerações finais}

Pudemos ver, então, uma quantidade relevante de aspectos que podem ser problematizados em torno da clínica e da produção do cuidado a partir das contribuições de autores, como Eymard Vasconcelos, oriundos do campo da Educação Popular em Saúde. Acreditamos que estes e outros desafios teóricos e políticos que foram colocados a partir da presente análise poderiam ser estendidos ao conjunto dos formuladores da Educação Popular em Saúde, pois há muita proximidade entre as formulações de Eymard e da maior parte dos pensadores desta matriz teórica.

Para concluir, reafirmamos que este trabalho buscava não apenas apresentar a compreensão de Eymard Vasconcelos sobre o cuidado em saúde e as ferramentas que oferece para operar a gestão do cuidado. Intencionávamos, também, delimitar os aspectos que o leva a desenvolver suas formulações, bem como identificar possibilidades de interlocução com outras perspectivas teóricas que estão se debruçando sobre a vida pulsante nos serviços de saúde com a mesma radicalidade de defesa da vida que a educação popular nos propõe como parâmetro ético. Esperamos ter logrado tais intentos.

É provável que não tenhamos esgotado todos os aspectos da produção de Eymard referente ao cuidado em saúde, nem apontado de modo exaustivo as possibilidades de interação com outros autores que debatem a produção do cuidado. De todo modo, reconhecemos as limitações deste material, que tem características mais próximas de um ensaio, propositivo, problematizador. Apostamos, com isso, que os companheiros implicados na luta pela saúde, no confrontamento fraterno, ajudem a identificar e tapar as brechas existentes nesta pesquisa, bem como a propor desafios não vislumbrados por nós. 


\section{Referências}

1. Gomes LB, Merhy EE. Compreendendo a Educação Popular em Saúde: um estudo na literatura brasileira. Cad. Saúde Pública. 2011; 27(1):7-18.

2. Gomes LB. A gestão do cuidado na educação popular em saúde: um estudo a partir da obra de Eymard Mourão Vasconcelos. Rio de Janeiro. Dissertação (Mestrado em Clínica Médica) - Faculdade de Medicina da Universidade Federal do Rio de Janeiro; 2010.

3. Merhy EE. O conhecer militante do sujeito implicado: o desafio de reconhecê-lo como saber válido. In: Franco BT, Peres MAA, Foschiera MMP, Panizzi M, organizadores. Acolher Chapecó: uma experiência de mudança do modelo assistencial, com base no processo de trabalho. São Paulo: Hucitec; Chapecó, SC: Prefeitura Municipal; 2004. p. 21-45.

4. Ferla AA. Clínica em movimento: cartografia do cuidado em saúde. Caxias do Sul: Educs; 2007.

5. Vasconcelos EM. Educação Popular e a Atenção à Saúde da Família. 4. ed. São Paulo: Hucitec; 2008.

6. Vasconcelos EM. A terapêutica médica e as práticas populares de saúde. Saúde em Debate. 1996;50:101-106.

7. Vasconcelos EM. Formar profissionais de saúde capazes de cuidar do florescer da vida. In: Vasconcelos EM, Frota LH, Simon E, organizadores. Perplexidade na universidade: vivências nos cursos de saúde. São Paulo: Hucitec; 2006. p. 265-308.

8. Mattos RA. Cuidado prudente para uma vida decente. In: Pinheiro R, Mattos RA. Cuidado: as Fronteiras da Integralidade. 3. ed. São Paulo: Hucitec; 2006. p. 119-132.

9. Vasconcelos EM. Educação Popular nos Serviços de Saúde. 3. ed. São Paulo: Hucitec; 1997.

10. Vasconcelos EM. A espiritualidade no cuidado e na educação em saúde. In: Vasconcelos EM, organizador. A espiritualidade no trabalho em saúde. São Paulo: Editora Hucitec; 2006. p. 13-157.

11. Cecilio LCO. A morte de Ivan Ilitch, de Leon Tolstói: elementos para se pensar as múltiplas dimensões da gestão do cuidado. Interface (Botucatu) [online]. 2009;13 (suppl.1):545-555.

12. Cecilio LCO. Apontamentos teórico-conceituais sobre processos avaliativos considerando as múltiplas dimensões da gestão do cuidado em saúde. Interface (Botucatu). 2011;15(37):589-599.

13. Merhy EE. Saúde: a cartografia do trabalho vivo. São Paulo: Hucitec; 2002.

14. Franco TB, Bueno WS, Merhy EE. O acolhimento e os processos de trabalho em saúde: o caso de Betim, Minas Gerais, Brasil. Cad. Saúde Pública. 1999;15(2):345-353.

15. Cecilio LCO.; Matsumoto NF. Uma taxonomia operacional de necessidade de saúde. In: Pinheiro R, Ferla AA, Mattos RA, organizadores. Gestão em Redes: tecendo os fios da integralidade em saúde. Rio de Janeiro: Abrasco; 2006. p.37-50.

16. Cecilio LCO. As necessidades de saúde como conceito estruturante na luta pela integralidade e equidade na atenção à saúde. In: Pinheiro R, Mattos, RA, organizadores. Os sentidos da integralidade na atenção e no cuidado à saúde. Rio de Janeiro: CEPESC/ UERJ, IMS: Abrasco; 2001. p. 113-126.

17. Merhy EE. Um dos grandes desafios para os gestores do SUS: apostar em novos modos de fabricar os modelos de atenção. In: In: Merhy EE, Magalhães Júnior EM, Rimoli J, Franco TB, Bueno WS, organizadores. O trabalho em saúde: olhando e experienciando o SUS no cotidiano. São Paulo: Hucitec; 2003. p. 15-35.

18. Donnangelo MCF, Pereira L. Saúde e sociedade. São Paulo: Duas Cidades; 1976.

19. Foucault M. Microfísica do Poder. 20. ed. Organização e tradução de Roberto Machado. Rio de Janeiro: Graal; 2004. 
20. Foucault M. A ordem do discurso. Aula inaugural no Collège de France pronunciada em 2 de dezembro de 1970. 11. ed. Tradução de Laura Fraga de Almeida Sampaio. São Paulo: Loyola; 2004

21. Deleuze G, Guattari F. Mil Platôs: capitalismos e esquizofrenia. Volume 2. Rio de Janeiro: Editora 34; 1997.

22. Vasconcelos EM. Para além do controle social a insistência dos movimentos sociais em investir na redefinição das práticas de saúde In: Fleury S, Lobaro LVC, organizadores. Participação, democracia e saúde. Rio de Janeiro: Centro Brasileiro de Estudos de Saúde; 2009. p. 270-288.

23. Campos GWS. A saúde pública e a defesa da vida. São Paulo: Hucitec; 1991.

24. Campos GWS. O anti-Taylor: sobre a invenção de um método para co-governar instituições de saúde produzindo liberdade e compromisso. Cad. Saúde Pública. 1998;14(4):863-870.

25. Campos GWS. Um método para Análise e Co-Gestão de Coletivos: a constituição do sujeito, a produção de valor de uso e a democracia em instituições: o método da roda. São Paulo: Hucitec; 2000.

26. Campos GWS. Subjetividade e administração de pessoal: considerações sobre modos de gerenciar o trabalho em equipes de saúde. In: Merhy EE, Onocko R, organizadores. Agir em saúde: um desafio para o público. 2. ed. São Paulo: Hucitec; 2002. p. 229-266.

27. Campos GWS. Saúde Paidéia. São Paulo: Hucitec; 2003.

28. Kloetzel K. Medicina ambulatorial: princípios básicos. São Paulo: EPU; 1999.

29. Merhy EE. O SUS e um dos seus dilemas: mudar a gestão e a lógica do processo de trabalho em saúde (um ensaio sobre a micropolítica do trabalho vivo). In: Fleury S, organizadora. Saúde e democracia: a luta do CEBES. São Paulo: Lemos Editorial; 1997. p. 125-143.

30. Vasconcelos EM. Educação popular como instrumento de reorientação das estratégias de controle das doenças infecciosas e parasitárias. Cad. de Saúde Pública. 1998;14 (sup. 2):39-57.

31. Carvalho LC. A disputa de planos de cuidado na atenção domiciliar. Rio de Janeiro. Dissertação (Mestrado em Clínica Médica) - Faculdade de Medicina da Universidade Federal do Rio de Janeiro; 2009.

32. Guattari F, Rolnik S. Micropolítica: cartografias do desejo. 7. ed. rev. amp. São Paulo: Vozes; 2005.

33. Lancetti A, Amarante P. Saúde mental e saúde coletiva. In: Campos GWS, Minayo MCS, Akerman M, Drumond Júnior M, Carvalho YM, organizadores. Tratado de Saúde Coletiva. São Paulo: Hucitec; Rio de Janeiro: Fiocruz; 2006. p. 615-634.

34. Dias NMO. Mulheres: sanitaristas de pés descalços. São Paulo: Hucitec; 1991. 
Gomes LB, Merhy EE. La educación popular y la atención de la salud: un estudio de la obra de Eymard Mourão Vasconcelos Interface (Botucatu). 2014; 18 Supl 2: 1427-1440.

El artículo analiza las concepciones sobre la atención de la salud en los autores de la Educación Popular en Salud, teniendo como obra de referencia fundamental lo que Eymard Mourao Vasconcelos publicó entre 1994 y 2009. Se trata de una investigación de la literatura, de naturaleza cualitativa, con nivel de análisis exploratorio y, además de la sistematización de las formulaciones de este autor, apunta a varias posibilidades para la discusión con los académicos en materia de la atención de la salud. Los textos se agrupan en las siguientes categorías: relaciones de poder en el cuidado en salud; críticas de la biomedicina; la atención individual; el acercamiento a la familia. Se trata de estimular la producción de los nuevos conceptos de la integración entre las formulaciones de los pensadores que no se han acercado, a pesar de las posibles similitudes temáticas.

Palavras clave: Educación Popular en Salud. Atención de la salud. Investigación cualitativa. 
